\title{
Collaboration of Communities and Non-Profit Organizations in Addressing Environmental Problems with African Countries
}

\author{
Ovruncsics Muszeros ${ }^{1}$, Kursmecs Girgő Zsult ${ }^{1}$ \\ Email: ovrucia.zeros@gmail.com \\ Faculty of Social Sciences, Corvinus University of Budapest, Hungary
}

\begin{abstract}
Environmental concerns concern the twentieth and twenty-first centuries' most pressing issues. This is because the threats found inside them are very deep and pervasive within the eco system itself. Humanity is actually seated on a ticking time bomb due to the environmental consequences of weapons and/or contamination, as well as threats such as flooding, wildfires, land degradation, wildfires, volcanoes, earthquakes, and radio-chemical hazards. Environmental issues have become a global issue for a variety of reasons; certain environmental problems are global in scope; concern for the environment becomes a global issue because an environmental problem has a global impact; environmental issues include the exploitation of global resources such as the oceans and atmosphere; environmental damage in one country can have an effect on the environment of other countries.
\end{abstract}

Keywords: Environmental, Humanity, Community

Received: March 3, 2021

Revised: March 30, 2021

Accepted: April 19, 2021

\section{Introduction}

Nigeria as a nation encompasses a variety of climates that necessitate the use of several physiographic units. There are several ecological areas, spanning from Sahel, Sudan, and Guinea savannas to rainforests, mangroves, and swamps. Different ecological zones react differently to the effects of human activity, owing to their inherent stress-response and carrying capacities. Sahelian savannas are especially susceptible to desertification; the Sudan savanna is barely coping with human pressure from its rapidly increasing population, firewood harvesting, and livestock grazing. Normally, the Guinean region is stressed as a natural buffer zone between distressing deserts and woodland belts.

The rainforest belt is under severe strain as a consequence of insufficient control and overexploitation of forest resources and other commercial activities, which has resulted in widespread land clearance. Compounding, particularly in the Niger Delta area, is a large-scale petroleum industry discovery, extraction, and processing operation that has left its mark through crude oil and petroleum product spills, problems associated with gas combustion, land destruction, and agricultural land depletion. Pollution of the soil and water, as well as threats to important ecosystems for fish populations. Soil erosion and gully formation, especially in eastern Nigeria, flooding of mangrove and low freshwater marsh seat belts, and unregulated logging with associated problems of damage and depletion of established habitats all contributed significantly to further exacerbations. A situation in which the world is worsening.

For the resolution of the cold war's security and military questions. International actors' response to environmental problems in the post-cold war period is dominated by a trend of collaboration that evolves in tandem with the rise of western dominance and the emergence of environmental consciousness in third world countries. This eventually removes the idea that environmental concerns are domestic political issues that must be held free of external intervention. Environmental issues have become a global issue for a variety of reasons; certain

Copyright ( 2021 , International Journal Papier Public Review, Under the license CC BY-SA 4.0 DOI: https://doi.org/10.47667/ijppr.v2i2.83 
environmental problems are global in scope; concern for the environment becomes a global issue because an environmental problem has a global impact; environmental issues include the exploitation of global resources such as the oceans and atmosphere; environmental damage in one country can have an effect on the environment of other countries.

Then there is the state's misuse of the same thing, and some instances are even transnational in nature, such as the annual smog between Indonesia and Malaysia. International politics of the environment is a term that refers to the mechanism through which countries conclude deals on environmental matters, either through the establishment of a government or by the establishment of the requisite international institutions. The mechanism entails the existence of an arrangement or negotiating process involving the environment that is being conducted by a state or organization, the existence of a regulation or regime requiring cooperation in the environmental sector, and the existence of disputes between political powers whose resolution is contingent upon the active interaction of environmental actors.

The method of applying the international environmental regime is a process in which tasks such as gathering, sharing, and debating knowledge about the fundamental reasons for the regime's existence are carried out by member states or other participants that concur with the regime's initial rationale. There is already a vast network of arrangements, treaties, instruments, and other rules of international law in place to govern environmental exploitation. Latest study has focused on international administrative agencies and the procurement process for environmental protection. The establishment of modern structures and the emergence of new values, such as the prudential standard, intergenerational rights, and environmental crimes, started to animate the negotiation table. The application of existing sources and concepts of international law, as well as a diverse range of related organizations, has resulted in a regulatory regime that, in the context of the environment, is regarded as international environmental law; nevertheless (Bodansky, 1999; Holland \& Foo, 2003; Krisch \& Kingsbury, 2006; Gunningham, 2009). The state has not yet been willing to forego the principle of sovereignty for the sake of interest.

\section{Global Environmental Issues}

Previously, it was believed that global environmental issues were mostly determined by natural variables such as nature, which included temperature, rainfall, humidity, and air pressure. With time, citizens realized that human actions also have a huge impact on the atmosphere and ecosystem. Consider deforestation, which has a local effect on temperature and rainfall. As the field of forest destruction expands, the resultant impacts become international in scope rather than local. Humans burned down trees for a variety of reasons, including commercial gain. In a national scale, a country needs foreign currency to keep the wheels of growth turning. Due to the country's lack of developed and strong industries, the only thing that can be exported to earn foreign currency is timber. The money and expertise needed to cut trees are modest and straightforward.

It is a global issue that has an effect on the climate as well; for example, the world population is growing at a breakneck pace. Population development entails the expansion of metropolitan areas and the consequent need for increased food supply. Not to mention the fact that electricity consumption is increasing.

Each of these requirements has an environmental impact. requirements for municipal and farm properties. To meet this need, forest land would have to be converted. The more water catchment regions continue to shrink, the greater the risk of a freshwater crisis. In the other side, many places with steep slopes are vulnerable to landslides, while the trees that once sustained the soil strength structure are dwindling in number. Then, as a result of decreased 
groundwater infiltration, surface water overflows occur. When these situations combine with cities' inadequate drainage facilities, flooding occurs. Floods can cause a variety of different types of pain. The immediate issue is the death and destruction of land. The indirect issue is the spread of multiple diseases such as malaria, dengue fever, and vomiting. We now shift our attention to the issue of energy extraction. Indonesia, for example, is already heavily reliant on petroleum-based energy sources. This reflects the government's and society's enthusiasm for the oil crisis. The government is perplexed on how to finance the state deficit, owing to the high cost of oil imports.

The public is perplexed because rising oil prices have a cascading impact on the price of commodities in the field. What I wish to highlight here is that from an environmental standpoint, and more precisely in terms of the composition of the air in the atmosphere, the usage of oil results in a rise in carbon dioxide $(\mathrm{CO} 2)$ gas. This pollution, along with five others, is considered to be the primary contributor to the global warming trend. Around 1990 and 2100, it is expected that the surface global temperature would rise by about 1.4 to 5.8 degrees Celsius. As a consequence of the melting of the polar icebergs, the global sea level would rise. Numerous parts of the earth would be flooded by rising flood levels. Climate change may occur on a large scale. Rainfall and floods are expected to rise. Certain infections would therefore see an uptick in outbreaks. Food plant output was also harmed. In a nutshell, there would be a major impact on human life.

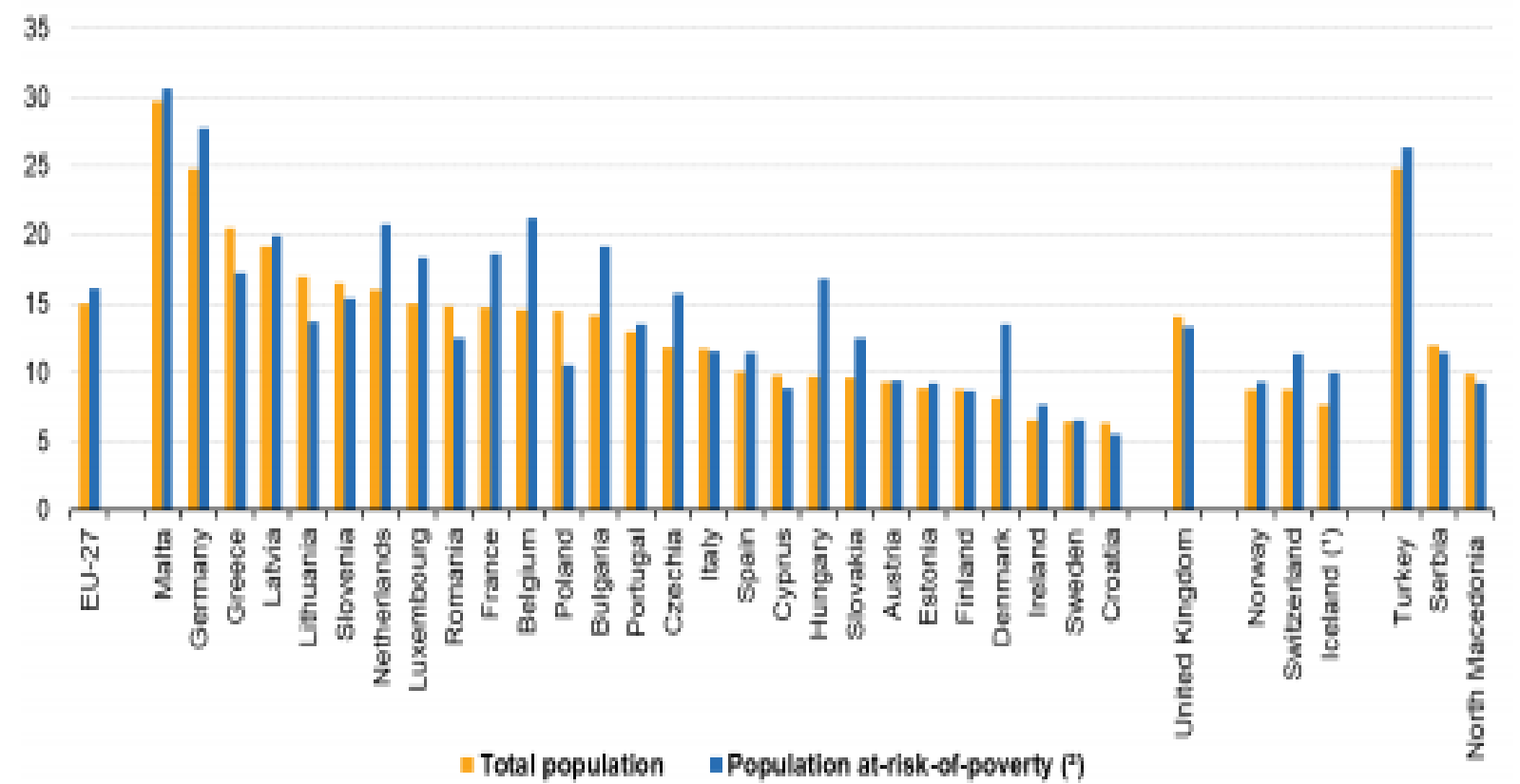

Figure 1. By income condition, the community is subjected to noise, grime, and other environmental issues.

Source: eurostat (2018)

Environmental researchers and experts are afraid by the prospect of a global disaster. The issue is that mankind's awareness of environmental issues is not uniform. This becomes more evident as one considers the degree of media consciousness in developed countries. Even among politicians, knowledge of this environmental issue is not uniformly spread.

In the face of the above circumstances, global pro-environment efforts started. The Kyoto Protocol is a relatively new convention that will remain in force until 2007. The Protocol's primary objective is to reduce the production of six gases that contribute to global warming. 
Between 2008 and 2012, a comprehensive assessment of the expenditure and consumption of these gases will be conducted in all countries that have signed this Protocol.

\section{Global Environmental Causes and Impacts}

Global Warming is a term that refers to the phenomena of global temperatures rising year after year as a result of the greenhouse effect induced by increased pollution of carbon dioxide, methane, dinitrooxide, and CFCs, which trap solar energy in the earth's atmosphere. The biogeophysical ecosystem has been impacted by the loss of polar ice, increasing sea water quality, desert extension, intensified rain and floods, climate change, disappearance of flora and fauna, and migration of fauna and pests (Ai et al., 2008; Williams, 2014; Brochier \& Ramieri, 2001). Impact on the community's socioeconomic activities: destruction of the coast and coastal towns, disruption of path, port, and airport infrastructure functions (Chang, 2016; Deshmukh, 2010; Petterson et al., 2006; Irazábal, 2018; Zsamboky et al., 2011). Disruption of human settlements and agricultural production Risk of cancer and disease outbreaks was increased

\section{Depletion of the Ozone Layer}

CFCs decompose and liberate chlorine atoms in the statosphere layer under the impact of ultraviolet radiation. Chlorine accelerates the conversion of ozone to oxygen dioxide, creating a greenhouse effect. Numerous other bromine-containing atoms, such as metal bromide and halon, also lead to the ozone depletion. Impact on living things: increased cases of melanoma skin cancer, which is fatal, increased cases of cataracts in the eye and eye cancer, decreased corn plant development, increased temperature and mortality of wild animals, and so on alternative.

Air contamination is a byproduct of the modern revolution. Pollution in the air can combine with rainwater, forming acidic compounds. The effect is that the corrosion mechanism accelerates, irritates the skin and respiratory system, and causes soil acidification. The rise in global population that occurs as a result of economic development is a challenge for the climate. The consequence: population development would intensify demand for natural capital and available land.

Desertification is the process of growing the land's capacity to support life. Desertification is a steady decline in fertility and erosion of the upper ground caused by human activity and a number of climate conditions such as drought and flooding. Affect: Initially, it had a local effect, but environmental considerations have also had a global impact, resulting in the expansion of vital land on the planet, reducing $\mathrm{CO} 2$ capture.

Biodiversity declines: is the diversity of living organisms. It encompasses not only the amount or sepsis of species in an environment, but also the biodiversity of species, genomes, and habitats, all of which are renewable natural resources. Since this biodiversity holds enormous promise for humanity in terms of wellbeing, food, and economy

B3 waste pollution (Hazardous and Toxic Products): materials known as explosive, flammable, destructive, radioactive, infectious, or corrosive. Impact: Formerly, it was just local, but now nations are included in the trade, with the limbs being deposited in the high seas. And if it occurs, the waste of dangerous and poisonous products may be serious, even to the point of death.

\section{Utilize Renewable Energy Resources}

The second approach to combat global change is to provide your house with green energies. Choose a service provider that generates at least half of its electricity from wind or solar and has been accredited by Green-e Energy, a non-profit agency that conducts independent 
assessments of sustainable energy alternatives. If this is not practical, you should use another method, which is to examine the size of your energy bill. Numerous utilities also have additional opportunities to promote clean energy in their monthly reports and on their websites.

\section{Energy Conservation}

The third approach to combat global change is to incorporate energy conservation activities into daily life. Heating and cooling buildings is one of the most energy-intensive everyday activities. Heating and cooling consume almost all of the electricity used in households. You will increase the energy efficiency of the room by sealing the air ducts and ensuring they are well insulated.

By buying and using energy-efficient appliances. After global warming became a serious concern, several changes have been made to the reliability requirements for different kitchen appliances and goods. When purchasing refrigerators, washing machines, and other appliances, search for the Environmentally Friendly label.

\section{Water Conservation}

The fifth approach to combat global change is to decrease water pollution. Conserving water may also contribute to the reduction of greenhouse emissions. This is because pumping, heating, and treating the water you use requires a significant amount of electricity. Therefore, reducing the shower period and turning off the water faucet when brushing your teeth is one way you can help combat global warming.

Additionally, you should go for WaterSense-labeled appliances and home appliances. According to the EPA, if only one of every hundred households in America was fitted with water-efficient appliances, almost 100 million kilowatt-hours of energy will be saved per year, avoiding 80,000 tonnes of global warming emissions.

\section{Conclusion}

Environmental issues are essentially a result of the global temperature rising year after year as a result of the greenhouse effect induced by increased pollution of carbon dioxide, methane, dinitrooxide, and CFCs, which trap solar radiation in the earth's atmosphere. It has developed into a global issue that impacts the atmosphere as well; for example, the global population is growing at a breakneck pace. Population development entails the expansion of metropolitan areas and the consequent need for increased food supply. Not to mention the fact that electricity consumption is increasing. With time, citizens realized that human actions also have a huge impact on the atmosphere and ecosystem. Consider deforestation, which has a local effect on temperature and rainfall. As the field of forest destruction expands, the resultant impacts become international in scope rather than local.

\section{References}

Al, W., ORKING, G., \& CLIMA, O. (2008). Climate change and food security: a framework document. FAO Rome.

Bodansky, D. (1999). The legitimacy of international governance: a coming challenge for international environmental law?. American Journal of International Law, 596-624.

Brochier, F., \& Ramieri, E. (2001). Climate change impacts on the Mediterranean coastal zones. Available at SSRN 277549.

Chang, S. E. (2016). Socioeconomic impacts of infrastructure disruptions. In Oxford research encyclopedia of natural hazard science. 
Deshmukh, A. R. (2010). Severity of social and economic impact due to flood damaged critical infrastructure on associated communities and industries (Doctoral dissertation, Purdue University).

Gunningham, N. (2009). Environment law, regulation and governance: Shifting architectures. Journal of Environmental Law, 21(2), 179-212.

Holland, L., \& Foo, Y. B. (2003). Differences in environmental reporting practices in the UK and the US: the legal and regulatory context. The British Accounting Review, 35(1), $1-18$.

Irazábal, C. (2018). Coastal urban planning in the 'Green Republic': Tourism development and the nature-infrastructure paradox in Costa Rica. International Journal of Urban and Regional Research, 42(5), 882-913.

Krisch, N., \& Kingsbury, B. (2006). Introduction: global governance and global administrative law in the international legal order. European journal of international law, 17(1), 113.

Petterson, J. S., Stanley, L. D., Glazier, E., \& Philipp, J. (2006). A preliminary assessment of social and economic impacts associated with Hurricane Katrina. American Anthropologist, 108(4), 643-670.

Williams, M. (2014). Climate change in deserts. Cambridge University Press.

Zsamboky, M., Fernández-Bilbao, A., Smith, D., Knight, J., \& Allan, J. (2011). Impacts of climate change on disadvantaged UK coastal communities. United Kingdonm: Joseph Rowntree Foundation. 